\title{
INTRODUCTION OF A METHODOLOGY FOR DEEP ENERGY RETROFITTING OF POST-WAR RESIDENTIAL BUILDINGS IN CENTRAL EUROPE TO ZERO ENERGY LEVEL.
}

Buildings are responsible for 35\% of greenhouse gas emissions released in Europe. The highest potential for reduction of the environmental impacts is in the existing buildings' energy efficiency improvement. The paper introduces a development of new methodology for a rapid deep energy retrofitting of existing buildings applicable to residential housing stock in Central Europe. It briefly describes the steps from production of building information model of existing building to complete renovation. It presents experience from pre-production phases on a case study from the Czech Republic. Technical and non-technical barriers to be solved in the near future are summarised in the discussion.

Keyword: Deep energy retrofitting, zero energy buildings, energy efficiency, residential buildings, renovation strategy.

\section{Introduction}

The European Union aims at the goal of erecting only nearto-zero operation energy level buildings after 2020; according to further-going Roadmap for moving to a competitive low carbon economy in 2050 [1], the European Council also sets the goal of 80 to $95 \%$ cuts in emissions by 2050 .

The building sector is one of the main energy consumers and emission polluters; about $40 \%$ of overall EU energy consumption together with about $35 \%$ of overall $\mathrm{CO}_{2}$ emissions release is attributed to buildings [2]. The construction industry is pushed tough for the highest possible energy and emission cuts. At least $3 \%$ of renovations yearly must comply with the low energy level to reach the EU's energy targets.

In the Czech Republic - as in any European country with long history - the building stock consists nowadays of rather old buildings. Most of dwellings have been built after World War II, when the demand for new building soared. Today, these buildings still present the largest group among all dwellings (see Fig. 1). To reach the environmental goals in the foreseen future, it is needed not only to build up the low energy buildings, but also to focus on the energy and emission cuts in the existing building stock.

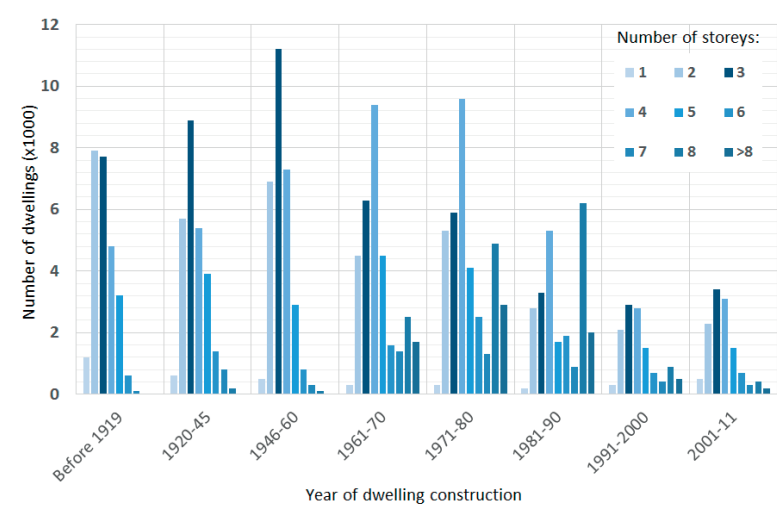

Fig. 1 Building stock in the Czech Republic (with former Czechoslovakia) [3]

For example, the recent requirements for the thermal resistance (or thermal transmittance) of the buildings' envelopes are driving the new construction automatically to a more sustainable operation of the buildings. The older building designs had to fulfil much less strict requirements, sometimes no limits for the energy performance were set in their year of construction. Figure 2 illustrates the development of the requirement for the mean U-value of building's exterior wall with openings in relation to various fenestration ratios. Just the operational energy cuts are definitely not the only goals that can be achieved to reach by

\footnotetext{
* ${ }^{1}$ Antonin Lupisek, ${ }^{1}$ Martin Volf, ${ }^{1}$ Petr Hejtmanek, ${ }^{1}$ Katerina Sojkova, ${ }^{2} J a n$ Tywoniak, ${ }^{3}$ Peter Op’t Veld

${ }^{1}$ University Centre for Energy Efficient Buildings, Czech Technical University in Prague,Czech Republic

${ }^{2}$ Faculty of Civil Engineering, Czech Technical University in Prague, Czech Republic

${ }^{3}$ Huygen Installatie Adviseurs, Maastricht, Netherlands

E-mail: antonin.lupisek@cvut.cz
} 
a refurbishment, but enhanced comfort level and higher quality of the indoor environment is usually expected these days. Many related parameters are required also by legislation. Summary of legal requirements was published in [4]. It can be though assumed that a simple refurbishment to the recently required quality level can bring significant savings and major quality improvement.

Although the straightforward idea, it means a very complex refurbishment process. To investigate the possibilities of energy saving renovations in the Czech Republic, the most frequent dwelling was chosen as a pilot building. Moreover, the refurbishment process was led to make more significant progress: the renovated building should reach nearly zero operation energy level in the same way like the newly-built houses after 2020.

The described situation is a starting point for a European project MORE-CONNECT under H2020 [5] which tries to solve the problem of complex renovations of existing residential buildings by developing prefabricated multifunctional renovation elements for the total building envelope (façade and roof) and installations and building services.

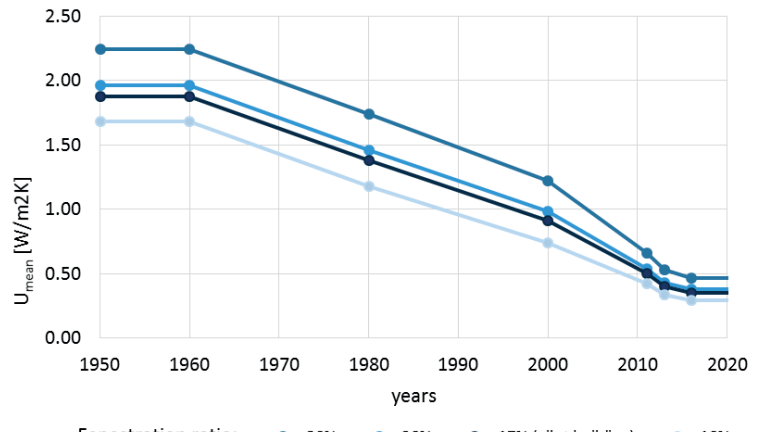

Fig. 2 The decrease of mean thermal transmittance (mean U-value) since 1950 for residential buildings for various fenestration ratios.

\section{Objectives}

The objectives of the design renovation process are based on a MORE-CONNECT project prerequisite that the energy consumption of a subject building has to be reduced from its actual level to net-zero level and the time needed for complex renovation of a block of flats shall not take more than 2 weeks (assembly on site). At the same moment there is a requirement for reduced negative environmental impacts, especially amount of embodied carbon dioxide equivalents.

The objectives of present paper are to introduce a novel renovation methodology designed in the project for postwar Central-European residential housing and to present an experience with application of the process from its beginning to pre-production phase.

\section{Methods}

The methodology comprises the following steps:

Assessment of the actual condition of the existing building and its operation;

Production of detailed building information model (BIM);

Analysis of today's energy performance;

Definition of clients' needs;

Design of technical improvements;

Energy simulation of building after implementation of designed energy-saving and energy production measures;

- Draft plan and time schedule of construction process;

- Design of planned measures in BIM;

(Semi-) automated production of modular elements;

Transportation on site;

Dismantling of old structures and preparation for installation of new elements;

- Assembly of new elements;

- Quality control;

- Commissioning and handover of finished renovation;

Monitoring.

The steps of the proposed methodology are closely described in the following sections.

Assessment of the actual condition of the existing building and its operation

Each building is a unique exemplary and has to be carefully probed. After the inception of the renovation process and general agreement with the investor, the first onsite inspection takes place. The main objective of this step is to collect the basic information about the building in question, but also to compare it with other similar buildings.

\section{Production of detailed building information model from a point} cloud obtained by scanning

The next step is to create an information model of the building. The model has to be detailed and accurate enough to enable export of information needed for energy simulations of the present state, for design and planning of the technical improvements and for pre-production modelling of each element.

For this task are usable several methods; the most suitable are laser scanning or photogrammetry. These techniques are provided by professional surveyors and the raw output is usually a digital map of the building in form of point cloud. To enable use of the obtained data for simulations and modelling the pointcloud, it has to be converted into a vector format, which can be to a high degree done automatically, but still usually some additional manual corrections of data are required. Additionally, information on building structures, used materials and basic properties of elements (such as windows, doors etc.) are added into the information model. 


\section{Energy analysis of present building}

In this step the information model is used for compilation of a simplified parametric representation of building's envelope. It is then combined with the information on building volume, the use patterns of whole building and individual apartments, data on number of buildings' occupants, data on historic energy consumption, local boundary conditions and localised climate data to generate a simplified energy calculation of building's primary energy demand.

\section{Definition of clients' needs}

In the next step the investor of the renovation is briefed about the results of the energy analysis and is guided through a list of choices of energy improvement of the building with the aim of defining potential variant sets of modules that can be added to the building to improve its usability, comfort, indoor environment and to reduce the energy demand of the building.

Design of technical improvements and energy simulation of building after implementation of designed energy-saving and energy production measures

Based on the interaction with the client, the technical variants are designed into detail using sets of modules that combined together form comprehensive renovation packages, which are modelled in BIM. Energy performance of each of the variant renovation packages is simulated and the results are together with visualisations, detailed descriptions and cost estimations conveyed to the investor in order to get a decision on choice.

Draft plan and time schedule of production and construction process

After selection of the renovation package, the whole production and construction process is planned into detail. The planning comprises design of all modules, their prefabrication and transportation to the construction site (just in time for assembly), preparation of the construction site, dismantling of old structures, installation of new components and assemblies, finalisation, quality control and final handover of finalised renovation to the investor.

\section{Pre-production design of modules in BIM}

Based on the selection of design variants by the investor, each module will be designed in BIM, which will automatically produce a bill of quantities and list of environmental impacts and embodied primary energy. The data will be transferred to the production facilities.

(Semi-) automated production of modular elements and transportation

Based on the BIM data, each element will be produced on semi- or full-automated production line, packed, labelled and then just in time sent to the construction site for assembly.
Dismantling of old structures, site preparation and assembly of new elements

The construction site preparation of a typical residential building includes preparation of the construction site by installation of dust and dirt protection and packaging of furniture, and handover of each flat, removing obsolete building components (windows, doors, roof elements or whole roof, building services, old pipes and wiring) and installation of anchors for new modules. The preparatory works are followed by a continuous assembly of the new external modules accompanied by connection of the internal installation and finished by cladding of roof elements and building integrated renewable energy sources.

Quality control, commissioning and handover of finished renovation

Depending on the variant, the finished installation of the renovation packages undergoes a standardised set of quality checks and commissioning of new building elements and technical systems. Each step is protocolled within the BIM, which is at the end of the process handed over to the building owner and can be used for facility management.

\section{Monitoring}

Higher levels of renovation packages include detailed set of sensors for complete monitoring of the regular operation of the building and preventive warning system which automatically sends alert messages in case of non- standard operational state occurrence.

\section{Results}

The proposed methodology was tested by project partners on several buildings representing the target buildings' typologies over Europe. The following sections present the experience from the practical application of the methodology on pilot building in the Czech Republic.

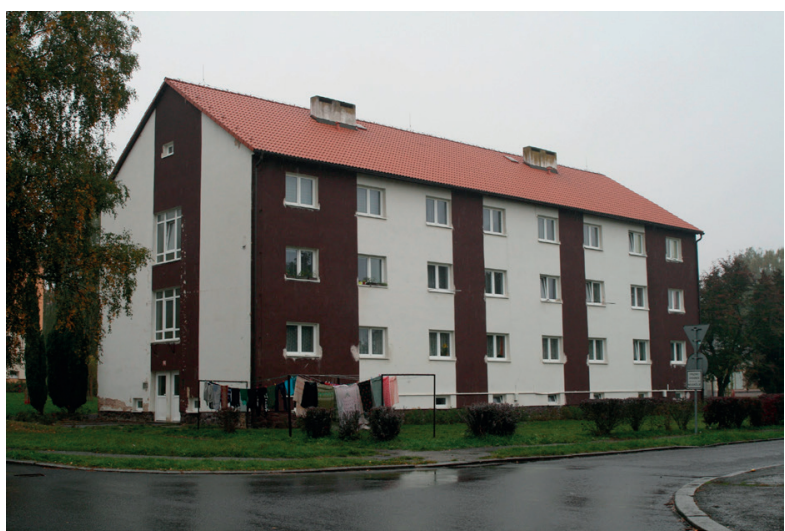

Fig. 3 The view of the pilot building in Milevsko in its present state 
Assessment of the actual condition of the existing building and its operation

The pilot building for the Central-European geo-cluster is a masonry residential house with a lateral load bearing system from 1950's in Milevsko (Fig. 3); the house is used as social housing. The building has a simple, rectangular floor plan, and a hip roof. It has three floors with 24 , similarly designed flats used with area of approx. $30 \mathrm{~m}^{2}$. The house has a usable floor area $995.3 \mathrm{~m}^{2}$ and energy related area $1107.3 \mathrm{~m}^{2}$. The fenestration ratio is $17.2 \%$. Typical floor height is $2.5 \mathrm{~m}$, each apartment has floor area of $35 \mathrm{~m}^{2}$. The building has a pitched wooden roof structure with ceramic tiles $\left(33^{\circ}\right)$ and is partly provided with cellars.

A reconnaissance to describe the weaknesses of the building was done. A number of problems was observed, such as an oldfashioned appearance of the house and devastated common areas, or the ruptures in the plaster. From the perspective of energy consumption, the original wooden windows' insulation level was considered insufficient, the users experienced winter overheating by dysfunctional control of heating system. An insufficient ventilation rates probably cause a mould growth in the basement floor, the leaking water-proofing amplifies the problem.

The deep renovation process has to take into account the causes of these problems. The overall energy performance of the building is planned to be improved, the poorly functional elements will be replaced and the failures fixed. The final design process is led up to solve the problems in the same time of one fast refurbishment.

\section{Production of detailed building information model from a point} cloud obtained by scanning

The age and original construction technology does not allow the simplification of the buildings' geometry, the facade cannot be assumed plain. To ensure the sufficient speed of renovation process, the $3 \mathrm{D}$ scanning or a digital photogrammetry is used as a basis for the building information model (BIM) development.

The comparative study was performed to show the possibilities of both technologies - see Fig. 4 [6]. Generally, both methods are convenient. Digital photogrammetry appears to be less demanding to perform in praxis, but not all cameras are precise enough.

The studies also showed the need for further development - the link between point cloud to a BIM model appears to be cumbersome; the current tools need large amount of human's support to deliver sufficient outputs for further production.

\section{Energy analysis of present building}

A preliminary analysis was performed to show the possibilities of the deep energy retrofit. The present state was modelled as a reference level. Building's mean $U$-value is $1.18 \mathrm{~W} /\left(\mathrm{m}^{2} \mathrm{~K}\right)$

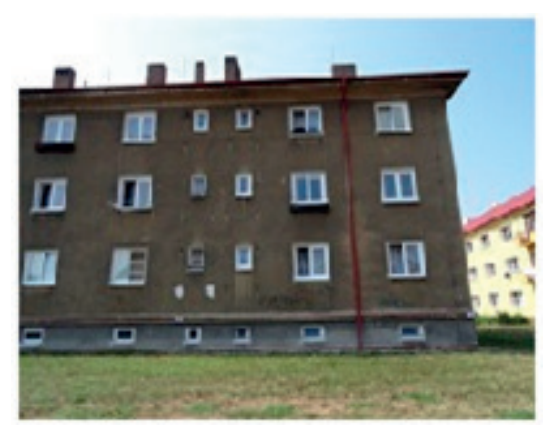

a)

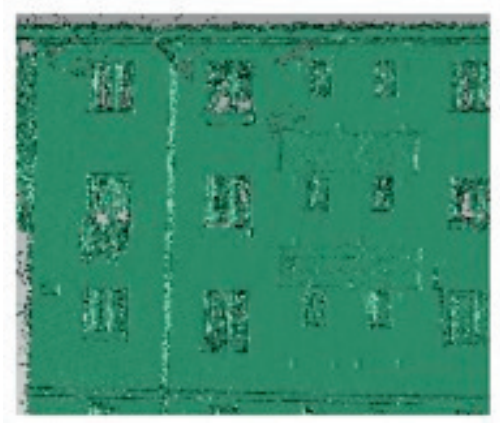

b)

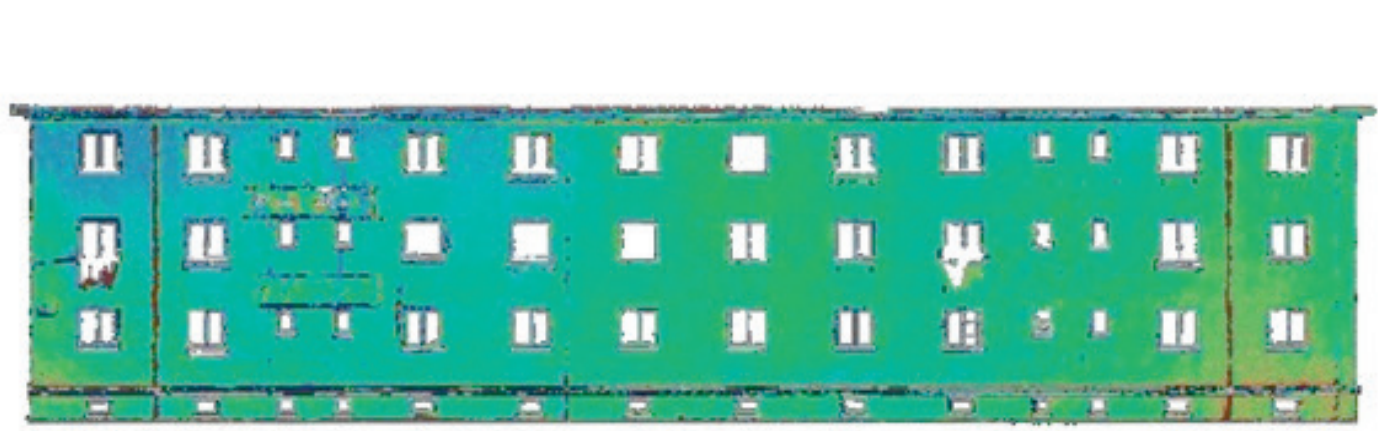

0.007

0.006

0.005

0.003

0.002

$-0002$

0003

Fig. 4 The best in-comparison performing digital camera's (Pentax 645D) outcomes:

a) original picture, b) a point cloud, c) accuracy of the final model (in metres) [6] 
which significantly exceeds the required value of $0.51 \mathrm{~W} /\left(\mathrm{m}^{2} \mathrm{~K}\right)$. The total heat transfer coefficient reaches $2037 \mathrm{~W} / \mathrm{K}$. The tota energy need for heating is $186 \mathrm{MWh}$, which corresponds to $168 \mathrm{kWh} /\left(\mathrm{m}^{2} \mathrm{a}\right)$. The building is connected to district heating system and equipped with traditional heating bodies. Total calculated delivered energy is $291 \mathrm{MWh}\left(263 \mathrm{kWh} /\left(\mathrm{m}^{2} \mathrm{a}\right)\right)$, annual consumption of non-renewable primary energy reaches $309 \mathrm{MWh}$ $\left(279 \mathrm{kWh} /\left(\mathrm{m}^{2} \mathrm{a}\right)\right.$ respectively).

\section{Definition of clients' needs}

Other step was to describe and fulfil the possible users' requirements as broadly as possible. The already finished refurbishment projects were considered together with the possible business plans. The investors can choose from many optional features to improve their building in number of combinations. To enable variability in the renovation offering, the three scenarios were set, all aiming at the zero primary energy building (ZEB) level:

a) Low-cost but complex ZEB renovation - economically the least demanding scenario; the building will reach ZEB level by refurbishment at minimum cost. This scenario contains no additional lofts or extra balconies, the technologies are designed at minimal needed level. A ventilation system with heat recovery, equitherm control system and an integrated photovoltaic system are installed.

b) Economic extension and renovation - ZEB refurbishment creates extra flats, the income from their sale partly covers the renovation cost. This scenario contains a new roof structure, roofing, individual room control system (user can control indoor climate separately for each room).

c) High-tech renovation (see Fig. 5) - this scenario tends to accommodate the best available technologies; the additional apartments in the duplex apartments are created (again to cover the refurbishment expenses), a new roof structure is created, and a model predictive control system (to adjust the operational control of the building by data obtained in real-time simulation in the mathematical model) will be installed. The flats may be provided with additional balconies or additional rooms. The new structures contain a vacuum

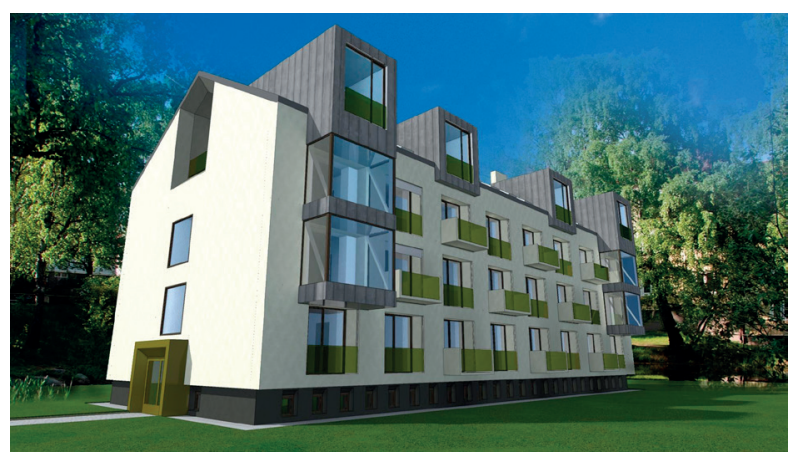

Fig. 5 The visualisation of the refurbished building - the high-tech scenario. insulation panels to provide a high insulation level $(\mathrm{U}=0.11$ $\left.\mathrm{W} /\left(\mathrm{m}^{2} . \mathrm{K}\right)\right)$. To the basic scenario is added a new wiring for cable TV or Internet routers to provide the user with all technologies at once and improve the standard of the building.

The elements designed for various scenarios can be used in arbitrary combinations.

Design of technical improvements and energy simulation of building after implementation of designed energy-saving and energy production measures

Three variants of energy improvement levels were developed:

1. Variant complying Czech nearly zero energy definition [7];

2. Variant leading to $80 \%$ reduction of primary energy use for space heating, ventilation, domestic hot water, pumps and other auxiliary energy;

3. ZEB level, i.e. the net primary energy use on annual basis is zero $\mathrm{kWh} /\left(\mathrm{m}^{2} \mathrm{a}\right)$, covering the same extent of needs as in the previous variant.

For each of the variants, combination of range of U-values with various kinds of energy sources supplemented with PV and/or solar thermal panels were considered within energy calculations to reach given (primary) energy consumption targets. Driven by the results of variant calculations, prerequisite basic level of $U$-values was set as follows: $U_{\text {walls }}=0.14 \mathrm{~W} /(\mathrm{m} 2 \mathrm{~K})$, $U_{\text {ceiling/roof }}=0.10 \mathrm{~W} /(\mathrm{m} 2 \mathrm{~K}), U_{\text {floor }}=0.32, U_{\text {windows }}=0.7 \mathrm{~W} /$ $(\mathrm{m} 2 \mathrm{~K})$, solar thermal transmittance of windows $g=0.5$. These values were used for the Low-cost but complex ZEB renovation and Economic extension and renovation scenarios. For High-Tech renovation scenario $\mathrm{U}_{\text {walls }}=0.11 \mathrm{~W} /(\mathrm{m} 2 \mathrm{~K})$ was assumed. Based on calculation of the heat loss of individual flats, considering given parameters of building envelope, warm air heating system with heating recovery has proved to be sufficient apart from the most unfavourable flat at Economic extension and renovation and HighTech renovation scenarios where supplementary heating would be needed during the coldest days. After retrofit, mean U-value $=0.23 \mathrm{~W} /(\mathrm{m} 2 \mathrm{~K})$ and calculated energy demand for heating at Low-Cost variant (geometry without changes) decreased to 24 $\mathrm{kWh} /(\mathrm{m} 2 \mathrm{a})$. Delivered total energy dropped to $67 \mathrm{kWh} /(\mathrm{m} 2 \mathrm{a})$ or $80 \mathrm{kWh} /(\mathrm{m} 2 \mathrm{a})$ for district heating and pellet boiler respectively. To achieve that level $254 \mathrm{~m}^{2}$ or $120 \mathrm{~m}^{2}$ of PV would be needed to reach ZEB level considering district heating or pellet boiler respectively.

\section{Pre-production design of modules}

The main design objectives were set before: the ZEB level of refurbishment, complex renovation process and high speed of retrofit process. Namely, the last objective pushes the design to prefabrication and additive technology; the original structure mostly remains and the new elements are added during the retrofit. A modular system was chosen as the most feasible solution. Apart 
from the most frequent standard wall and roof modules, the preproduction showed the need of auxiliary modules: roof extension, corner, entrance or gable modules etc. - see example of a division of building envelope into modules in Fig. 6 .

The CAD and 3D BIM model was used to illustrate all the technologies in the modules. The virtual design process pointed out the problematic details in the structure and missing or noncomplying elements. These need to be designed or adjusted to its final form to fit in the system. On the other hand, every newly designed element creates new expenses and must be though further optimised.

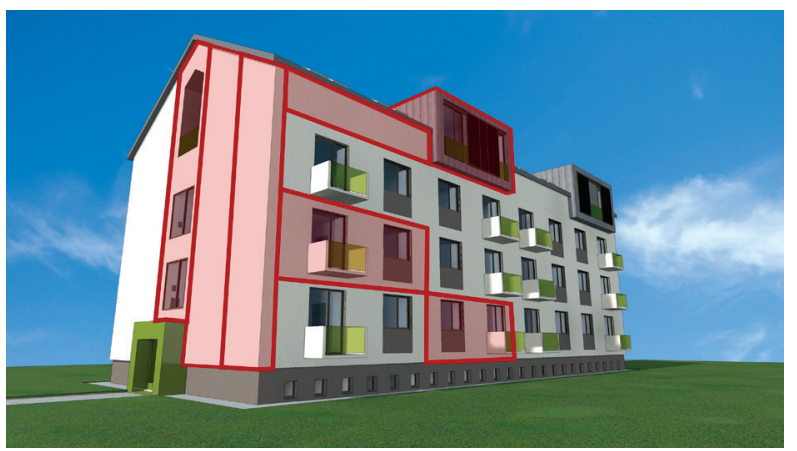

Fig. 6 An example of building envelope's division into retrofit modules

The production phases will be subject of further research in the MORE-CONNECT project.

\section{Discussion}

During the work on the Czech projects were identified various non-technical and technical barriers that limit the applicability of the proposed approach.

\section{Non-technical barriers}

Some of buildings' owners are mentally locked in the typical scenario of step-by-step renovations, which includes at some point replacement of old obsolete windows (usually for new low-cost double-glazed with plastic frames) and then later on installation of an external thermal insulation composite system (ETICS). Independently on the previous steps roof covering gets replaced when needed. The problem is that the owners of buildings are usually not well informed about all available options for advanced retrofitting enabling rapid installation (and thus reducing the negative effects of construction); improvement of the indoor environment by installation of mechanical ventilation system with heat recovery, controlled by $\mathrm{CO}_{2}$ concentrations; new installations of cabling for data networks and TV; possible addition of new balconies; integration of shading devices; and building integrated solar systems.
Another type of barrier is represented by the economic feasibility of complex renovation. The feasibility parameters are strongly dependent on the socio-economic situation of the tenants and their willingness or even possibilities to pay extra for improved standard of living. The barrier can be mitigated by seeking for additional sources of finance, which can come for instance from adding new flats for rent or sale in roof extension of the building.

\section{Technical barriers}

One group of technical barriers depends on the potential for rapid development of production technologies in the near future. For example, at the moment a manual polishing of data is still needed in the process of scanning of building envelopes and conversion of point-cloud data to BIM, but it is expected that this step soon becomes automated. Another leap forward is needed to enable to connect the building information modelling phase more tightly with the production phase. At the same moment the obsolete manual production of prefabricated elements is due for replacement by highly flexible automated production lines, which will represent a significant shift in construction practice (as drafted for instance in [8]).

Another group of technical barriers is represented by limitations resulting from the parameters of the existing building. For instance, there is limit for the thickness of the additional external thermal insulation layer imposed by the dimensions of windows and related requirements on indoor daylight factors. It can be solved with help of superinsulation (as shown for instance in solutions developed in [9 and 10]), but with a significant improvement of project cost. Another restriction by dimensions is for new ventilation ducts, wiring, piping or even new boilers and heat storage tanks. Some of the installations can be led directly in the facade modules (leading in some cases to need of superinsulation due to limited space in the facade thickness) or in new building extensions dedicated to these installations. Building extensions can be in some cases used also for installation of new energy sources.

\section{Conclusions and future work}

The up to date usual step-by-step partial renovations of buildings do not represent a systemic solution to achieve nearlyzero and zero primary energy levels. With the advancing climate change a rapid renovation action is needed. Modular retrofitting with use of prefabricated elements might not be suitable for all existing buildings, but there is a significant portion of building stock, for which this approach is advantageous. As shown on the pilot building, the described methodology offers several scenarios of renovation, each of them utilising set of prefabricated modules that can be variably combined to offer a broad variety of options to the potential investors. Such approach to deep energy 
retrofitting generally seems to be viable, however, there are still some challenges in process waiting to be solved. While the $3 \mathrm{D}$ scanning and use of its outcomes for modelling seems to be manageable, the main challenge will be in close interconnection of the pre-production and the production phases. Also some nontechnical challenges still wait to be tackled.

The complete design and production process will be further validated and improved during the remaining time of the MORECONNECT project duration and it is expected to be proven on real retrofitting projects in partnership with a selected municipality owning suitable buildings.

\section{Acknowledgements}

The project MORE-CONNECT has received funding from the European Union's H2020 framework programme for research and innovation under grant agreement no 633477. This work has been supported by the Ministry of Education, Youth and Sports of the Czech Republic within National Sustainability Programme I, project No. LO1605.

\section{References}

[1] European Commission: A Roadmap for Moving to a Competitive Low Carbon Economy in 2050, 2011.

[2] Directive 2010/31/EU of the European parliament and of the council of 19 May 2010 on the energy performance of buildings

[3] ANTONIN, J.: Housing Stock and Energy Savings Possibilities Survey. Prague : Czech Green Building Council; 2014.

[4] KALAMES, T. et al.: What Kind of Requirements nZEB and Deep Renovation Sets for Building Envelope? Proc. of Central Europe towards Sustainable Building 2016, Prague : Czech Technical University, 2016; in print

[5] MORE-CONNECT: Concept and Approach [online]. 2016 [cit. 2016-05-30]. Available from: http://www.more-connect.eu/theproject/concept-and-approach/

[6] MATOUSKOVA, E., FALTYNOVA, M.: Advanced Geomatics for Modular Building Reconstruction (MORE-CONNECT Deliverable 4.1), Prague, 2016.

[7] Regulation No. 78/2013 Sb. About Energy Performance of Buildings (in Czech), Ministry of Industry and Trade of the Czech Republic, 2013.

[8] MICIETA B., BINASOVA, V., HALUSKA, M.: The Approaches of Advanced Industrial Engineering in Next Generation Manufacturing Systems. Communications. Scientific Letters of the University of Zilina, vol. 16, No. 3a, 2014, 101-105, ISSN 13354205, 2013.

[9] KOBLER, R., L., et al: Retrofit Module, Design Guide. EMPA, March 2011. ISBN 978-3-905594-60-7.

[10] TYWONIAK, J., LUPISEK A., BURES, M., VOLF, M.: Wood Based Curtain Wall for Building Retrofit - Development and Performance. Proc. of Advanced building skins 2015 Conference, Graz : Graz University of Technology, 2015, 213-218. ISBN 9783-85125-397-9. 